\title{
Balancing Work and Life: Whose Work? Whose Life? Whose Balance?
}

\author{
Glenda S. Roberts ${ }^{\dagger}$
}

\begin{abstract}
As the developed nations increasingly see women's participation in the labor force rise, a common challenge has become how people can balance work responsibilities with the rest of their lives, be it family, household chores, hobbies, or other personal interests. The crux lies in putting into place and enforcing policy frameworks that acknowledge the legitimacy of finding balance, without sacrificing gender equality. This paper discusses the parameters of this problem for Japan, a low birth-rate, rapidly aging society with growing numbers of women who seek to maintain careers. Through a study of the working situations of employees at one U.S. multinational corporation in Tokyo, I investigate the ways in which career women approach and negotiate work/life balance. In recent years, while government and corporate policies have changed to foster both balance and gender equality, a cultural work environment that breeds long hours for core white-collar workers, embedded gender roles, an ongoing recession, and a lack of strict enforcement mechanisms for corporate work/life balance initiatives and their legal underpinnings seriously dilute the effectiveness of policy. Balance is precarious at best, and often elusive.
\end{abstract}

A society ages either because its people get older, or because they have fewer babies, but usually both. ${ }^{1}$ At the other end of the problem of the aging society is another problem familiar to all countries of the Organization for Economic Cooperation and Development (OECD), and one which has caused considerable consternation in Japan for over a decade: the "low-birthrate society." Japan's total fertility rate in 2000 of 1.36, when projected into the future, yields a scenario whereby three, out of every ten, Japanese in 2025 will be over 65 and on a pension. ${ }^{2}$ The aging, low-birthrate society will be a strong impetus for restructuring the gendered post-war pattern of work in Japan, typified by a breadwinner husband and his homemaker/part-time working wife. Japan is currently in a transitional state, whereby policies supporting gender equality and dual-career families are increasing, but the practices and sentiments attached to the postwar system of employment and that culture of work, remain. This is not unique to Japan.

What we now have in the West, too, is an employment model built with the assumption of a former age: that a full-time care-giver will be present in the home to nurture the nuclear or extended family, or what Arlene Appelbaum and others refer to as the "unencumbered worker-devalued caregiver model." Now that fulltime homemakers' ranks are thinning fast with the rise of women's participation in the labor forces of all OECD countries, however, societies are left with the problem of how to replace

\footnotetext{
${ }^{\dagger}$ Professor, Graduate School of Asia-Pacific Studies, Waseda University
} 
their unpaid labor, or how to give workers, male and female, the flexibility and time to perform both paid and unpaid labor.

The breakdown in the traditional gendered division of labor has caused many nations to create family policies to encourage the birthrate upward as well as to aid people in maintaining or achieving some quality of life (maintain health and wellbeing, foster gender equality, aid in rearing the next generation). There is considerable variety in these policies, with some focused more on subsidies and services for childbearing and rearing in general, including supports for mothers who do not work outside the home, while others focus on creating infrastructural supports for dual-earning couples or single working parents. The OECD's Working Party on Social Policy defines "Familyfriendly" policies as "those employment-oriented policies that facilitate the reconciliation of work and family life by fostering adequacy of family resources and child development, increase optimal allocation of labour market resources, and promote gender equality in employment opportunities." In this paper, I focus particularly on "Family-work reconciliation policies," or, "All those measures that facilitate the reconciliation of work and family life by fostering both the extension of family resources and parental labour market attachment." Some such policies are dictated by law (such as Japan's Child Welfare Law of 1947, that mandated the establishment of public day-care centers), while others are the initiatives of the private sector (such as daycare provided within a corporation).

Underlying many such policies is a consensus that childbearing and rearing, as well as eldercare, or "care work," pose an unequal burden on women due to the gendered division of labor, and, as a consequence, women have fared worse than their male counterparts economically as well as in the power structures of their societies. If societies want their birthrates to increase, they have to make the social contract fairer for women. As Nancy Folbre puts it, we are constrained from equality by gendered social policies and frameworks including the institution of employment itself: "The lack of flexibility in work hours, resistance to accommodating the demands of family labor, emphasis on continuous work experience-all of which are typically explained as methods to enhance work efficiency-are far more efficient for employers and for men than for women, children, or society as a whole. These structural aspects of paid labor can be reformed only by gender-conscious strategies that are also conscious of other collective identities and interests." 5

The challenge, then, is to create a social infrastructure that will promote gender equality in the home and in the workplace; one that will offer real options to people to pursue their goals, rather than simply rhetoric. This turns out to be more of a challenge than it might seem, because it requires fundamental changes in the ways people think about work, in the ways they think about the household division of labor, and in the ways they regard the labor of "caring. "It requires nothing short of a revolution against the Victorian "male breadwinner/female homemaker" model which has been so strongly entrenched in Western societies, and, in the post-war period, in Japanese society. ${ }^{6}$

In this paper I will consider some of the governmental policy initiatives that seek to foster a social environment more conducive to the reconciliation of work and family life for men and women. I will then discuss briefly the situation of women's employment in 
Japan and the general work environment that they currently face. Finally, I will use data from a case study of a multi-national corporation in Tokyo to suggest where the cutting-edge corporate environment actually stands and how employees cope in relation to such initiatives. Ultimately, I find cultural and structural difficulties facing work/life balance and gender equality in Japan may not be easily solved.

\section{The Low Birth-rate Society, Gender Equality, and "Family Friendly" Workplace Policy}

In the United States, as well as in the United Kingdom (UK) and European Union (EU), the twentieth century has seen increasing diversity in household patterns. The changes reflect the increase in lifestyle choices including rising divorce rates, increasing numbers of single parents, unwed parents, same-sex couples, childless couples, singles, older parents, and increasing longevity. ${ }^{7}$ At the same time, most of these nations are facing declining birthrates, so that their population growth is well below the replacement level. As Eileen Drew sums it up, "The shift towards delaying or abandoning marriage, choosing one or no children and living longer all point towards population decline and possible labour shortages in the future."

Linked to the trends in household diversification is a widespread erosion of a gendered division of labor in these societies, what Appelbaum refers to as "the traditional breadwinner-homemaker system of paid work and unpaid care." 9 While I do not have the time to extensively treat the notion of care in this paper, it is intrinsically bound up with the valuation of women's work in the market. Furthermore it is viewed largely as women's responsibility, whether or not they perform paid work as well. ${ }^{10}$

While the family demographic changes noted above have been considerable, the rates of women's employment have grown remarkably, and policies to foster gender equality have been put in place. Eileen Drew, Ruth Emerek, and Evelyn Mahon note that changes in the gendered division of labor have been slow to materialize in the European Union: "Although there have been observable shifts from the 'breadwinner'/ 'housewife' contract to an 'equality' contract, this has served to force women into a dual role and there is an evident lack of adequate change in men's behavior."11 The same has been found for the United States. ${ }^{12}$ In other words, although women's opportunities for equal employment with men in the developed world are greater now than they have ever been, there has not been a corresponding equivalent shift of men taking up care-work in the home.

For the past several years I have studied the discourse of the "low birth-rate society" in Japan. Media concern began at the "1.57 shock" of 1989, when the birthrate plunged below the one-time sudden dip of the "special year of the horse," in $1966 .{ }^{13}$ Over the past twelve years since then, the downward trend has continued. Japan does not have the lowest fertility rate of the OECD; those of the Mediterranean countries are lower. Nevertheless, the decline has received not a little public attention. ${ }^{14}$ As the birthrate in Japan dropped, the government began to make legal infrastructure to uphold the principle of gender equality (Equal Employment Opportunity Law, 1986, 1999; Basic Law for Gender Equality, 1999), and has produced policy initiatives to relieve women of the burden of childbearing, childrearing, and eldercare, such as the Angel Plans of 1995 and 2000, the Nursing Care Insurance Law of 2001 and the Childcare Leave Law and 
Childcare/Family Care Leave Law of 1991 and 1999. ${ }^{15}$ Government publications have come out with strong statements acknowledging the structures of constraint under which women and men operate in Japanese society, and government deliberation councils have urged the removal of many of these constraints. I am not suggesting that the low birth-rate alone has been responsible for these policy trends, but feminist scholars on strategic government committees who have seized the opportunity to make their mark have identified the constraints of the gendered division of labor as a main cause of the low birth-rate. If the constraints against mothers' labor force participation can be loosened, so the reasoning goes, and social supports are created to make work and family rearing more compatible for both women and men, then the birth rate may increase again, or at least the economy will remain afloat. ${ }^{16}$

While pro-natalism is certainly not on the agenda of Japan's feminists, gender equality is, and the low-birth rate environment has proved to be an excellent breeding ground for some radical initiatives toward a gender-equal society. Despite these forward-thinking laws, however, Japan lacks the social consensus necessary to put these progressive laws and initiatives consistently into action, whether at the level of the individual, the household, the corporation, or in other social institutions. ${ }^{17}$ Much of the "family-friendly" legislation passed thus far is dependent on the "administrative guidance" by the government ministries. They encourage the law to be put into practice, and as a result, practice often falls short of the law. I should add here, while many of Japan's laws could be considered "family-friendly," there is no specific package of laws expressly labeled as such, nor are there specific policies to encourage large families, out of remaining distaste for the explicit pro-natalism of the war-time government.

The main reason behind the Japanese government's encouraging workplace flexibility is its desire to ensure women's contributions to the economy as members of the labor force in the coming years, as well as its hope that flexibility and social supports for working parents may encourage them to have more children than they would have had otherwise. Here I would like to discuss the report published by the "Fuamirii Furendorii" Corporation Research Group titled, Aiming for 'Family Friendly' Corporations (hereafter FFC), and edited by the Women's Bureau of the Ministry of Labor in $2000 .{ }^{18}$

What is required of a firm for it to be deemed "family-friendly" by the government? First, a firm must have systems in place that make possible the harmonization of work and household, and prove that these systems are being utilized. Second, the firm must have systems that allow one to follow a flexible work style that takes into consideration the balance between work and household. Third, it must have a corporate culture that facilitates the harmonization of work and household. ${ }^{19}$ The list of "family-friendly" provisions is actually quite long; one Ministry of Labor survey in 1996 and 1999 consisted of eleven: "regulations regarding childcare leave," "financial support for childcare," " system for shortened work hours," "flextime system," "system for moving up or moving back of start time and end time," "exemption from overtime," "regulations regarding family-care leave," "in-house daycare," "financial assistance for family care," "care leave for sick family members," and "re-employment system." 20 Furthermore, "family" is defined as not only households of married couples and their children, but diverse families including single people. The targets of these policies are not only women but men as well, and the concept "family-friendly" also incorporates the notion 
of cultural change within the firm, not only in the provision of systems. ${ }^{21}$ Not included in this survey, but considered flexible work arrangements, are telecommuting, sabbatical leaves, and job-sharing.

According to the FFC report, in encouraging flexible workplaces, Japan is falling somewhere between the EU, the UK, and the United States. They report that in Europe, workplace flexibility is not simply a matter between labor and management, but the "family-friendly society" is an explicit national goal, and they aim to give roles to the household, labor unions, corporations, regional public entities, and the state, as well as distribute the family responsibility within the household to both men and women. The national and regional public entities plan the preparation of the infrastructure for childcare, eldercare, and providing leave systems for child and elder care with some level of income guarantees from social insurance systems. Labor and management, then, through labor management consultation, put into practice pay and leave systems that exceed the legal stipulations.

The FFC report finds that in the UK and United States, on the other hand, because people strongly oppose public authority interfering in household matters, public infrastructure for childcare and eldercare has not made much progress, so corporations, rather than the government, have taken the lead in building daycare centers, establishing diverse flexible leave systems and pay systems. The FFC report also remarks that it is in the UK and the United States that we see the confidence that being "family friendly" is also a plus to the corporation's profit-seeking. I interpret this as meaning that if it were not profitable, corporations would have no reason to pursue familyfriendly policies, since these are practices largely not mandated by the public sector, at least not in the United States. In fact, the U.S. government itself is apparently reluctant to extend to government workers paid parental leave that some workers in the private sector enjoy. Three House of Representative members are attempting to get the paid parental leave for federal employees, but the International Herald Tribune reports, "The legislation will very likely not win support from the Bush administration. In November, the Office of Personnel Management said it had studied the issue and found little evidence that offering paid parental leave could stem turnover or improve hiring." 22

Furthermore, the FFC notes that in the United States and UK, "family-friendly" does not stop at consideration for family only, but has to be extended further to "work/ life," although the report does not elaborate further on this difference. This is an important point. In the case of the United States, at least, there are a fair number of individuals who resent favorable treatment or consideration that extends only to people with children, as they feel having a child is a personal choice with personal consequences, and others should not have to bear the responsibility for those consequences. Hence, U.S. corporations have had to develop policies that allow everyone, not only parents, flexible work/life options. The FFC report goes on to conclude that, in Japan, the main proponent of "family-friendly" infrastructure (especially in regards to childcare and eldercare) is the public sector. In this way, Japan shares many elements with the Continental model: "In order to sort out the basic idea of why we ask corporations to become family-friendly, it is surely appropriate that the basis is the way of thinking of the Continental model, such that together with the national and regional public organizational levels, it (family friendly) should be thought of as a social obligation of 
the corporation." 23

As the FFC report notes, these factors do not mark the end of the debate among Japanese. Rather, in the present difficult economy, where corporations have to restructure in order to survive against international competition, and where they must reconsider the system of personnel management in use up to now, it is necessary to capture fully the flavor of the UK/U.S. "family-friendly" model that sees "familyfriendly" as having a positive effect on the management of the firm, especially in terms of recruitment, retention, and lowered absenteeism. In sum, they note, "It probably cannot be something that just makes the corporate side's burden heavier." 24

\section{"Family-Friendly" Policy in Japan's Firms Today}

To what extent the government can sell the "family-friendly" ideal to firms in the current bad economy is a big question. Keep in mind the comment of the FFC that "family-friendly" should not merely increase the corporate burden. So far in Japan, larger firms have a higher rate of establishing such systems for their employees than do small and medium-sized firms. ${ }^{25}$ (I should note here that, theoretically, an employee should be able to take advantage of his or her legal rights to government-mandated "family-friendly" policies whether or not the firm has actually established them as a system). The tendency for large firms to be more likely to incorporate the "familyfriendly" legal framework into their personnel policy systems may be due to large firms' higher rate of unionization and generally firmer financially grounding. Since the majority of the working population is employed in small and medium-sized firms, this bodes ill for the prospect that "family-friendly" policies will catch on quickly.26 In the United States, too, this has been the case: in a recent study of the responsiveness of small businesses to work/family issues, researchers found that small businesses (with between 1 and 49 employees) were less likely to provide policies or programs, whether on a formal or informal basis. They also found that large firms offered a wider variety of formal policies and programs than smaller business (sounder finances and economies of scale were reasons noted). ${ }^{27}$

On the other hand, firms of any size in Japan may be more likely to aim for more flexibility if only because the government is encouraging it as a kind of good corporate citizen behavior, although this is much less likely to occur, I think, during a recession. One government official told me that firms see "family-friendly" as a luxury (zeitaku). Their subcontractors say, "If you're going to go so far as to establish family-friendly policies, why can't you raise the rate you pay us for each piece we sell you?" The two manufacturing firms I visited in Aomori in February, 2002, who had won Family Friendly Awards from the Ministry of Health Labor and Welfare, also stated that the main thrust behind their instituting their policy framework was the fact that their parent company had already done so and was encouraging them to follow suit. That is, it was not out of a conviction that establishing such policies would be profitable for the company, or that Childcare Leave and Family Care Leave are now the law of the land, but out of a commitment to follow the general policy trends of the main company, that these firms began instituting "family-friendly" policies. ${ }^{28}$

In the above-mentioned Ministry of Labor survey, the most well-established "family friendly" policy in place in Japan's firms is Childcare Leave (CCL). In 1999, 98.7 percent 
of large firms with over 500 employees had systems for childcare leave, while 53.5 percent of all firms had such systems in place. The second most frequently institutionalized practice is Family Care Leave (FCL), at 96.8 percent for large firms, and 40.2 percent for all firms. The rate of establishment of "family-friendly" policies has been quite rapid in large firms since $1996 .^{29}$ While some firms may informally allow flexible work arrangements without actual policies, Hiroki Sato notes that in firms where these practices are not institutionalized through rules and regulations, employees have difficulty in making use of them (regardless of whether some of the policies, such as $\mathrm{CCL} / \mathrm{FCL}$, are mandated by law, I might add).

Finally, CCL and FCL are not mandated by law for people who are day laborers or who are employed under a contract, such as paato ${ }^{30}$ and temporary workers. This is quite problematic, for instance, for women who work as contract workers and renew their contracts with the same dispatch firm, as they are not eligible for these CCL/FCL benefits. A revised CCL/FCL took effect in April 2002.31 The news article that discussed these changes in the law reported that as the care leave for children's illnesses is not mandated but only encouraged, and as there are no stipulations for it to be paid, some corporations would refuse to make it a paid leave, and some would refuse non-regular employees the right to make use of it.

Japanese working women also have rights to paid pregnancy leave: the Labor Standards Law (1947), amongst other provisions for pregnant working women, guarantees 14 weeks of maternity leave and upholds women's right to work after marriage and childbirth. Next, the Child Welfare Law (1947) established publicly funded daycare centers. While in the post-war period, government employees such as teachers regularly made use of these laws to hold careers, women in private companies have had to fight marriage and pregnancy bars, government regulation notwithstanding. ${ }^{32}$

\section{The Changing Face of Gender in Post-War Japan}

Thus far I have established that Japan's society, along with most of its OECD neighbors, is experiencing population decline from a low birthrate, as well as aging. But what are the social trends behind these demographic facts? Briefly, in this section, I will introduce survey data on some of the changing values regarding lifestyles in Japan in order to illustrate some major shifts in thought on "appropriate" gender roles.

Because of such reasons as the desire to continue working, to remain free of the social burdens that accompany the statuses of "bride" and "mother," and to continue enjoying a high living standard, many women are delaying marriage, and some eschew marriage altogether. ${ }^{33}$ The average age at first marriage has increased steadily in recent years. In 1972, the average age of first marriage for men was 26.1 , while for women it was 22.9. In 2000 , it had climbed to 28.8 for men, and 27.0 for women. The "White Paper on People's Lifestyles" notes that, to understand the background to this phenomenon, one must look at societal and attitudinal factors. ${ }^{34}$ For instance, the 1997 Basic Survey of Fertility Trends found that almost 90 percent of the unmarried people surveyed felt that they would marry at some point in their lifetimes, but over half reported that they would not marry until they found their ideal mate. Moreover, the "People's Lifestyles Choice Survey of 2001" found that a significant proportion of young people feel that one can lead a satisfying life even if one does not marry, while many fewer of those in their 
Figure 1 Opinions on Life without Marriage

Can you have a satisfactory life without marriage?

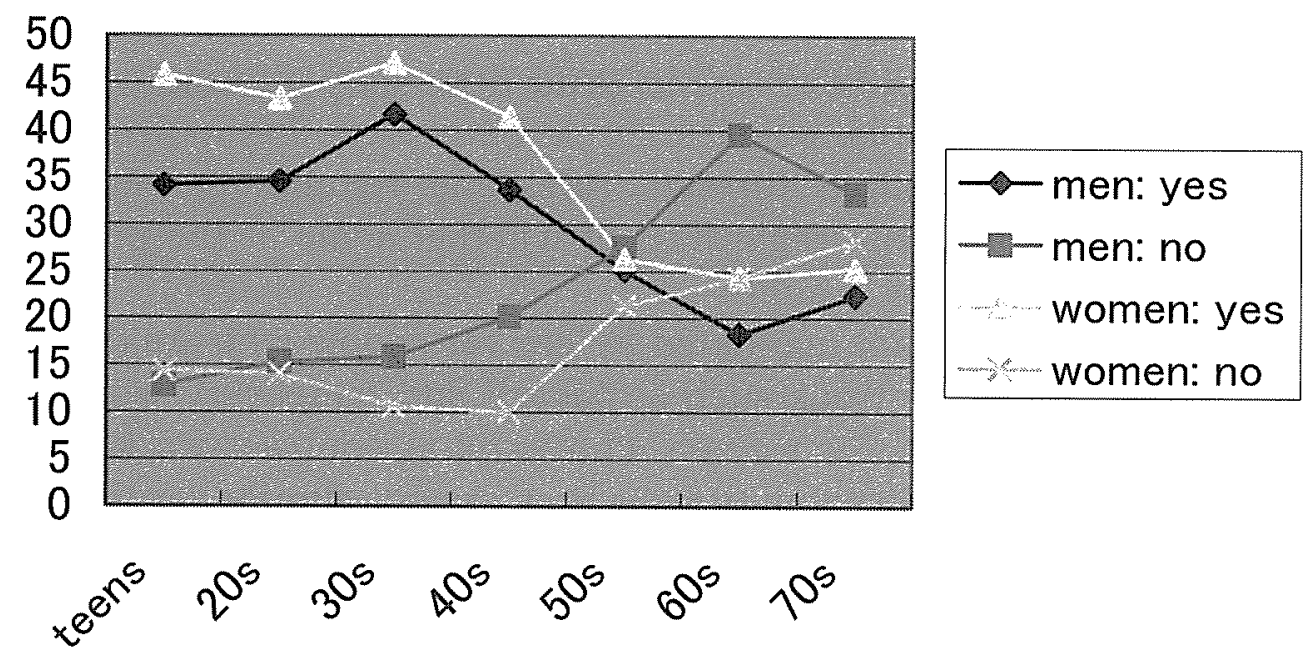

Source: Kokumin Seikatsu Hakusho Heisei 13 Nendo [White Paper on People's Lifestyles for 2001], Tokyo: Naikakufu (Cabinet Office), 2001, p. $15 .{ }^{36}$

fifties and up felt this to be true. ${ }^{35}$ Another interesting point found in this survey is that more young women than young men feel that they could lead a satisfying life without marriage: while 43.3 percent of women in their twenties and 47.1 percent of women in their thirties agreed, the rates for men in those respective age groups were 41.7 percent and 33.7 percent. Moreover, the trends diverge with age. The wider gap between men and women in their thirties may indicate that men at this age are hitting their highest/ most demanding career strides and feel that marriage might lessen their daily burdens in some respects. It could also be that as young men grow older they are under increasing pressure from their companies to marry. Women, on the other hand, might enjoy their jobs and freedom, and feel that marriage would impose unwelcome constraints (such as having to quit their jobs and be responsible for a household). By the time they are in their thirties women's families may exert less pressure to have them marry. Further research is necessary to reach a definitive answer for the discrepancy.

Unlike other OECD countries, in Japan, few children are born out of wedlock, so the number of children born within marriage assumes great importance. While infertility plagues some couples, others choose not to have children from the start, or restrict their number. The "White Paper on People's Lifestyles" reports that the drop in the total fertility rate to 1.57 in 1989 was a result of delayed marriage, but that the continued drop after that is due to couples having no children or fewer children. While 79.7 percent of married women aged 25-29 had one or more children living with them in 1980 , in 2000 only 61 percent had the same number of children living with them. In the 35-39 year old age group, in 198094.2 percent of women lived with one or more children; this had dropped to 87.5 percent in $2000 .{ }^{37}$

The costs to Japanese women of the gendered regime of labor are certainly not insignificant. The Nikkei Weekly stated, 
Balancing Work and Life: Whose Work? Whose Life? Whose Balance?

Figure 2 Wives' Employment by Age of the Last Child Born mothers' labor force participation

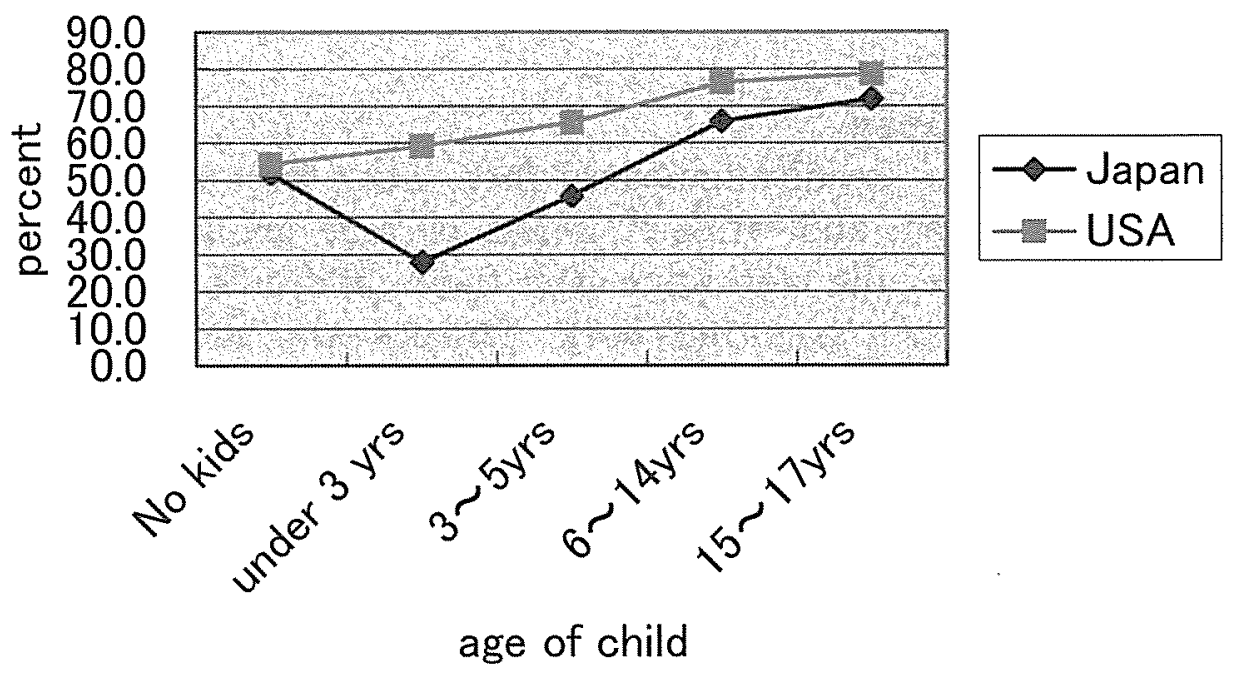

Source: Kokumin Seikatsu Hakusho Heisei 13 Nendo [White Paper on People's Lifestyles for 2001], Tokyo: Naikakufu (Cabinet Office), 2001, p. 58. ${ }^{39}$

More women leave their jobs after marriage and childbirth in Japan than in the U.S. and Europe. The fertility rate among women who keep their jobs is extremely low. The government estimates that junior-college graduates will earn 180 million yen $(\$ 1.44$ million $@ \$ 1=125 y e n)$ less during their lifetimes if they leave their full-time jobs after childbirth for part-time work. Little wonder that many are increasingly reluctant to have children. ${ }^{38}$

Figure 2 well illustrates the effect of childbirth and rearing on women's employment in Japan, as compared with the United States. Although women without children exhibit similar participation rates, Japanese women's labor force participation drops greatly with the presence of children under three years of age, only recovering after the children are school-aged:

Although in recent years the Japanese government has strengthened the infrastructure for women to remain attached to the labor force, and while the Ministry of Health, Labor and Welfare encourages corporations to provide more flexibility to both male and female employees so that they may balance work and life, many, if not most, corporations are far from exhibiting the "family-friendly "ideals propounded by the Ministry of Labour. In fact, even companies that receive "family-friendly" commendations from the Ministry may still harbor plenty of contradictions, since workplace culture is so difficult to amend. Currently Japan seems to be developing some potentially fruitful policies to support gender equality in employment and in the home, but individual women and men report mixed feelings about their abilities to successfully utilize these policies. Perhaps the recent government poster promoting Childcare Leave sums it up. Picturing a cartoon of a father carrying his son on his shoulders, the caption reads, "Towards a society where fathers can take childcare leave." The bubble text from the father reads, "If you're a man, why don't you fulfill your responsibility as a father!" Until recently, 
most men felt that their main responsibility as father was fulfilled in the very fact of their total time commitment to the firm. Now the notion of fatherhood is changing to one that demands hands-on participation, yet corporate culture is still one that adheres to the previous definition. ${ }^{40}$

\section{The Culture of Work in Japan}

Although women have steadily increased their labor force participation over the past four decades in Japan, and while it is has become commonplace for married Japanese women to re-enter the workforce after their children are of school age, their re-entry is usually restricted to part-time work. The post-war pattern in large corporations has been that employers allot the stable "regular" jobs to men, the "corporate warriors" and from them they expect total commitment, expressed in long hours of work and loyalty to the firm. Because women are viewed by employers as ephemeral, and peripheral employees, they are not generally expected, nor are they encouraged, to remain in the workplace for the span of their careers. Rather, they take on the entire responsibility for managing the home, their children's educations, and the health of their families. ${ }^{41}$ This gendered division of labor, teamed with other socio-institutional infrastructure (education, tax system, social welfare system, legislation) that supports large corporations, has been termed the "corporate centered society" (kigyo choshin shakai). ${ }^{42}$

While the Equal Employment Opportunity Law of 1986 did result in some corporations allowing a few women to become female corporate warriors, it did nothing to change the baseline masculine standard of the "regular employee" job, which requires the counterpart of a "professional housewife" to make family life possible. Because of the incompatibilities of career and home life in Japan, many Japanese women reject this "corporate warrior" model for women, and place more emphasis on their roles as mothers, homemakers, and community activists, in which they have considerable authority and for which they garner a strong measure of cultural respect. ${ }^{43}$ Indeed, since there remains significant cultural respect for the full-time homemaker in Japan, institutionalized in the tax system and pension laws, one wonders whether the Arlene Appelbaum construct of the "unencumbered worker-devalued caregiver" sums up Japan's situation as accurately as it does the situation of women in the United States. As mentioned earlier, however, these days, Japan's increasingly highly educated young women seem in much less rush to get to the altar and start having families. Examples of this trend are seen in the statistics of one corporation that I surveyed in Tokyo in 1999. The corporation, which I will call "MNF" for "Multinational Finance," is composed

Figure 3 Distribution of MNF Employees, by Sex

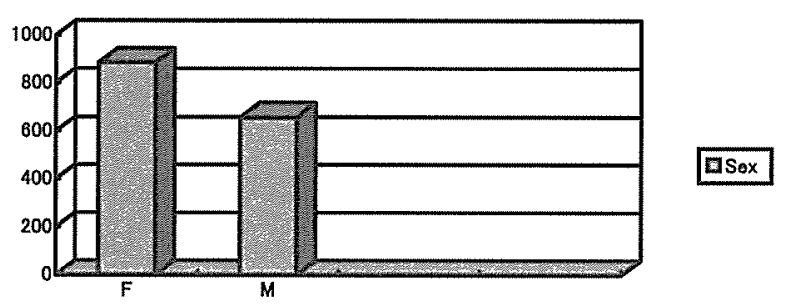

Source: MNF company data, 2001. 
of over one thousand employees, with women making up just over half.

The norm for marriage among male employees at MNF appears very strong, with 75 percent of men aged 31-40, 90 percent of men aged 41-50, and 96 percent of men aged 51-60, married. For women, marriage is less prevalent: only 37 percent aged $31-$ 50 , and 27 percent aged 51-60, are married. The women's marriage rate is markedly lower than that for Japanese women in general. One could speculate that for a man, a career without a spouse is a challenge, while the opposite is true for a woman.

\section{Balancing Work and Life at MNF}

There is no better way to understand the nuances of family-friendly policies in Japan than to follow employees as they experience these policies in their lives. Beginning in 1999, MNF, a U.S. multinational firm with a branch company in Tokyo, began to implement several flexible work arrangements, in addition to the CCL it had on board since 1991. I studied the implementation of the earliest new policies being offered to MNF male and female employees in Japan. In the next section, after a description of MNF, I will discuss workers' opinions of flexible work arrangements, focussing especially on how employees negotiated pregnancy and childcare while building their careers. Do flexible work arrangements truly offer employees the choice of remaining on the job and building their careers? Does it give employees "work/life balance?" The answer is complex. I begin with the background of MNF's decision to offer more flexibility to its employees.

MNF has a long history in Japan, having established its first office in the early years of the twentieth century. Over 93 percent of its employees in Japan are Japanese. Currently, the firm has operations in numerous countries world wide, with thousands of workers. MNF is one of tens of U.S. financial services firms in Japan's market. Over the course of the research, between April 1999 and January 2002, I have interviewed or conducted focus groups with some 87 employees about their experiences with, and strategies for, work/life balance, and queried their opinions of MNF's recent policy initiatives along these lines.

\section{Work/Life Policy in the United States}

Since MNF is a U.S. multinational, I should briefly discuss the sort of influence MNF received in implementing flexible work arrangements, as it was, in part, stimulated by

Figure 4 Employees at MNF, by Hiring Category

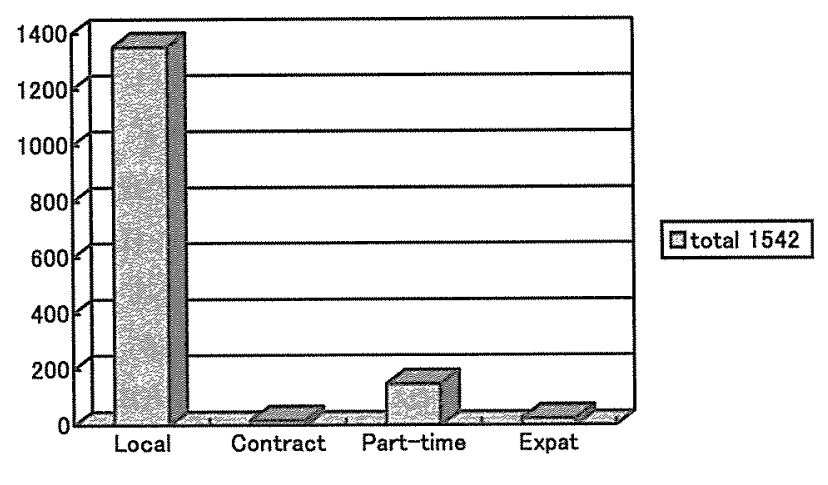

Source: MNF Company Data, 2001. 
what had gone on in the headquarters back home as well as in other international branches. Basically, in the United States, as the male breadwinner/female homemaker pattern broke down beginning in the 1970s, an increasing number of parents in the workplace had sole or shared responsibility for dependents, and these people were having difficulties trying to fulfill their responsibilities toward their families when the workplace required the same rigid commitment as it had under the male breadwinner model. Since the 1980s, MNF in the United States had implemented a panoply of flexible work arrangements to assist its employees with balancing their work and home lives. This is typical of large U.S. firms as noted by the FFC report cited earlier: in the United States, many "family-friendly" policies are created at the discretion of the private sector rather than mandated by state or federal law. MNF was a strong and expanding firm that needed to attract outstanding employees. Offering flexible work arrangements was in this sense, too, seen as a positive feature in recruitment retention, and in boosting employee commitment to the firm.

\section{MNF Japan and the Introduction of Flexible Work Arrangements}

MNF has a corporate policy to the effect that it must comply with the laws of the country in which it is sited. Thus, it has offered CCL as a policy since 1992, and FCL was introduced in 1999. Furthermore, career female employees report that MNF's attitude toward women in terms of training and promotion improved during the latter 1980s, when the Equal Employment Opportunities Legislation (EEOL) came into effect.

In 1999, MNF decided to implement some of the flexible work arrangements (FWAs) already in place in its U.S. operations, as a pilot study, and to expand them if they proved successful. Up to this time, flex-time was the only FWA offered at MNF Japan. The firm was expanding in Japan despite the recession, and needed to both attract and retain good workers. The rationale for expanding flexibility was that MNF had been losing some talented female staff due to the women's difficulties balancing work and family lives. This trend was especially important because MNF had been treating female and male employees on an equal basis, and had hired many female 4 -year college graduates as well as MBA holders. They had a strong interest in retaining them. Hence, the top management decided to take action along several lines, and announce the new policy under the agenda, "Managing with Flexibility." The major new policies were reduced hours for regular workers and implementation of a "bring your kids to work day." ${ }^{4}$ The personnel department held firm-wide seminars emphasizing the legal framework of CCL/FCL and the firm's backing of it, as well as explaining the new reduced-hours policy.

\section{Troubles Implementing Family-friendly Policies at MNF}

The top managers were willing to introduce these measures, but they also noted that there could be resistance to flexibility at the mid-managerial level, for a couple of reasons. One is that many mid-managers are brought in to MNF from previous employment in Japanese firms and they lack the mindset of the MNF culture, which tends to be oriented more toward an individual's targets and getting the job done at an intense pace during the work day. In contrast, the Japanese, white-collar work culture is seen as one where the day is much longer, interspersed with socializing, and workers 
are not expected to leave if others in the section still have jobs to finish.

Another roadblock to implementation that top managers noted is that, while MNF's culture tends more toward gender equality, managers who come in from more traditional Japanese banking environments will not be used to this and may not feel that retaining female employees is desirable. Yet, I have seen this work both ways; sometimes the Japanese managers' expectations give women more flexibility. For instance, in one case, a manager who was from the United States felt that his employee was being given too much flexibility by the CCL provision of up to one year of leave after the child's birth, since women in the United States have only three months stipulated in the Family Medical Leave Act (FMLA), and most return to work before that. ${ }^{45}$

MNF has recently made acquisitions of Japanese companies that are perceived to have a very different, more conservative managerial culture. MNF Japan's top personnel manager expressed doubt as to whether these new acquisitions would be convinced of the efficacy of flexible work initiatives. The long hours of overtime evidenced in some sectors of MNF were also seen as strong barriers to the implementation of FWAs.

\section{MNF's New Policies: Telecommuting, Family Sick Leave, Back-up Care}

MNF instituted a pilot program for telecommuting in 2001, but it is still too early to know the result. To date, three women, all managers and all with infants or toddlers, have taken it, and I have interviewed two of them. Neither woman seemed to feel that telecommuting was an easy solution, although it helped them manage for a brief period. Difficulties in accessing information easily, as well as emotional turmoil at being home but not being "on call" for the baby when he cried, were mentioned as drawbacks. Both women seemed happy to be back in the workplace. When I interviewed an MNF personnel manager in January 2002, he noted that the firm was considering introducing a Family Sick Leave (FSL) policy, that would allow paid leave in half-day units with the equivalent of five working days per year as the maximum number of days available. The half-day units could be used by those employees who had family members, within the second degree of relationship or family members living with the employee, who needed medical care or attention. This is in addition to the policy newly in place as a flexible work arrangement, which allows employees to take vacation days in half-day increments. The manager thought that FSL would be implemented.

After studying the presence of a felt demand for on-site daycare in 2001, MNF had originally hoped to establish a regular daycare center in cooperation with a few other firms in the area, but this did not pan out, as one multinational corporation reported they could not afford to fund it due to the recession, and another Japanese firm wanted its female employees to quit, not stay on through childbirth. The subsequent plan to institute a small in-house back-up daycare room was also put on hold for a number of reasons.

To sum up, although operating in Japan during the recession, MNF decided to implement more flexibility beyond that legally mandated, out of an interest to recruit and retain highly educated female employees. These are not average workers, but are, in many cases, highly educated and sophisticated people, comfortable in international settings and capable in Japanese and English languages. As a foreign firm, MNF had trouble attracting the best of new male recruits from the top universities, who prefer to 
enter Japanese firms. Achievement-oriented women, on the other hand, see in foreign capital firms the opportunity for promotion they are often barred from in Japanese firms.

From any angle, these women groomed themselves for careers, and they were highly interested in achieving a balance between work and life. Most of those I interviewed were actively trying to make this balance, as they were either expecting a child or had recently had one or more children. Through inquiring into their strategies and perspectives, we can better discern how they accomplish this balance, and gain a sense of how stable it might be. Here I shall introduce some of the particulars of how some women at MNF balanced work and life.

\title{
MNF Female Employees and Specific Challenges they Face in the Paid Labor Force and in the Home Nurturing Careers
}

Many of MNF's female employees have nurtured careers, in a sense, since they were children. They engage in focused study in preparation for the entrance exams for four-year universities and then, when accepted to such institutions, major in subjects rarely chosen by women such as law or economics. This was no coincidence; my interviewees noted that their choices were deliberate and gave them an edge in the labor market upon graduation. But it was not their choice alone: it was also their mothers' choice. Several women noted that their own mothers had been homemakers, but had wished to have careers originally. Mothers strongly encouraged their daughters to enter good universities and major in fields that would lead to good jobs. When I asked one informant (b1964) what had made her decide to major in economics, she replied,

\begin{abstract}
Ah, based on the suggestion of my mother, because my mother, would also have liked to get a job after educating her children, but she couldn't get a job, because she has been just a housewife, so she had no experience of working in a company. So she hoped her children would get into a major or famous company and work for a long time because her children's experiences are her own experiences (laughs).
\end{abstract}

Another interviewee (b. 1953) noted that she grew up witnessing her parents' very unhappy marriage and her mother's inability to get out of it due to a lack of financial independence. This spurred her into college and propelled her into a career before her time. She graduated from a respectable national university with a degree in economics, and got a job at a large Japanese machine manufacturer. She remarked,

I wanted to walk the same course as men. In those days women went into literature or education and became teachers. But I wanted to work in the same sphere as men. I had a lot of confidence because I was young (laughs).

The Japanese firm, however, did not know what to do with her as they were only used to using women as office clerks. They would give her a challenging job, only to pull her out of it as soon as a new young man came along whom they really wanted to train. 
Balancing Work and Life: Whose Work? Whose Life? Whose Balance?

Another employee, (b1966), worked for a Japanese securities firm for over four years after graduating in 1990 from a respectable private university in Kansai where she had majored in diplomatic history. She wanted more training opportunities, however, and she noticed that it was always males who were selected to go abroad for Masters of Business Administration (MBA) studies. So she went ahead and applied for MBA programs on her own, thinking that she could ask the firm for a leave of absence if she were accepted. As it turns out, she was accepted at a famous business school in the United States, whereupon she asked the personnel department for the leave. The department summarily rejected her request, saying that the male candidate they had fielded for the same business school had been rejected. When she graduated from the MBA program, needless to say, she did not seek to return to a Japanese firm.

\section{Balancing with Husbands}

Although most women did not have husbands who had time during the week to do any housework or childcare except perhaps to drop the baby off at the daycare center in the morning, many did do fathering and some of the housework on weekends. One interviewee, who had a very difficult time when her eight year-old child began to refuse to attend school, was urged by her child's teacher, as well as by her in-laws, to quit her job, but her husband never asked her to do so; he expected that she would always continue to work.

Another worker had a husband employed in a very busy government ministry where he came home in the early-morning hours on a regular basis. When they decided to have a child, he applied for a secondment to a less busy institution, and he was able to stay there for two years. This enabled him to come home at a reasonable hour, and proved to be enormously helpful for his wife during her pregnancy and the baby's first year of life.

A third person was able to convince her husband to start doing household work when both of them were in graduate school abroad, before they had a child. I must emphasize, however, that this was exceptional. Most of the women I interviewed were performing the majority of housework and childcare on top of their work loads.

\section{Birth Timing and Limitation}

Establishing a career in the firm took a good deal of time, training, and effort. Women wanted to be perceived as professionals, and they worried that giving birth, or even getting married, might make their bosses think they would lose interest in their jobs. Some women waited to have a child some two or three years after assuming a new post in order to be known and respected by their co-workers and boss first.

Furthermore, many of the women I talked with had one or two children and indicated they would have liked to have another if they thought they could still manage. Most women indicated that they could not. I did speak with one woman, though, who was a mother of three. None of the three children were planned/expected. She managed her career by getting by with four hours of sleep a night, and by relying on a combination of natal, in-law, and daycare center support. She was also very energetic and focused. 


\section{Caring for Families: Pregnancy, Birth, and Concerns of Working Parents}

For many women, the decision to have a baby was quite deliberately made and planned, even to the preferable month to give birth, so as to get the child into the public daycare center. One informant noted that her decision to have a child was spurred by a website for working moms that she had found, called Mugibatake. Another mentioned that she was encouraged to have a child when three women ahead of her in her section all got pregnant yet stayed on the job. Those three ended quitting their jobs either during or after maternity leave, but she had her baby and stayed. Yet another said she was the pioneer in her section and served as a role model for other women who chose to have children and continue working.

\section{Pregnancy}

The announcement to one's boss that one was pregnant was often made with some trepidation, and some women waited much longer to tell their co-workers, lest the pregnancy be cause for concern. Most women noted that their bosses at MNF took the news well, although this was not always the case. One employee, at the managerial level, told me,

When I told my boss about the pregnancy, he said, 'What am I going to do with your report-who will cover for you?' If I didn't write it, then he would have to do it. But I was able to finish everything before my due date. I promised him I wouldn't take any training nor any vacation. He said congratulations only after that.

Many women took advantage of the corporation's flexible hours policy in order to arrive early or late and hence miss the rush hour traffic. Most people have at least an hour and some even more than two hours' commute each way. Some employees, at considerable expense, moved to locations nearby the office so that they could avoid commuting entirely. The area around MNF was also known for having more open spaces in public daycare than most wards.

\section{Birth}

Maternity leave of 6 weeks before and 8 weeks after birth has been well instituted at MNF for several years now, though some non-Japanese bosses needed to be instructed about this provision and its implications for the company. Out of concern for finishing as much work as possible before going on leave, some women did not take the full 6 weeks. Most first-time mothers return to their natal homes for the duration of maternity leave, although with the second child, they stay in the Tokyo area. While most Japanese firms would frown on a man taking off extra days during childbirth and its aftermath, the husbands of the women I spoke to were usually present at the births, due to felicitous night and/or weekend timing of the birth! Some husbands also accompanied their wives to doctor's visits, formerly the role of one's mother or motherin-law. 


\section{Childcare Leave}

CCL, which began in 1991, is frequently taken, and is welcomed by the women, who say it allows them to recover more fully from childbirth, and get to know and have confidence in parenting their new child. It also allows the child to gain enough weight to have better sleeping patterns by the time the mother returns to work. Perhaps most important, for those whose children are born late in the year, CCL gives them the time to place the child in a public daycare center before they must return to work (such centers have long waiting lists). From the parenting viewpoint, CCL seems to make a lot of sense; one woman pointed out that putting very young babies into a daycare situation does not work very well since they have not yet developed immunities and end up getting every illness that comes along. From the career angle, though, there is always the possibility that one's favorite job may be gone if one takes a long leave, or one's boss may have changed. The latter is a daunting challenge as it is very difficult to convince a new person that one is a serious and talented worker when he sees one going out the door to retrieve children from childcare every day at $5: 30$, or even before.

The strategy of utilizing CCL is always a daunting task; the busy public daycare centers generally have long waiting lists. This is where care offered by the extended family can make or break a woman's career. In one case, a woman who could not find daycare for her baby asked her retired father to come live with her family for the first year after the baby's birth in order to look after the child until the child could enter a daycare center. Her mother was looking after the elder son's children so she was not available. The father agreed, and the arrangement was working out. He returned home to his wife on the weekends.

Another problem with CCL is that it is seen as a woman's prerogative only. Although the policy is written to welcome either parent to take it, or for it to be shared in succession, the fact is that no men have yet been brave enough to sign up. Like a military draft, one of my interviewees noted that CCL should be mandated by law. Another said she felt it was unfair that men's desires to parent, such as wanting to pick up their children from the daycare center or trying to get home on time to have dinner with the family, are not acknowledged. Now that her child is seventeen, she has taken a job that requires less overtime on purpose so that she can go home in time for dinner and engage her high-school son in conversation every evening. She regrets not having done so earlier in her career. In my observation, prevailing notions of masculinity will not allow men to assert their identities as partners or fathers except as breadwinner. It might be a bit easier to get men to take CCL, though, if it were better remunerated. The length of CCL taken is variable and some women wish to return to work as soon as possible. One woman who returned to work after maternity leave, told me,

I wanted to work as much as I can. I didn't have the confidence that I could be away from the office that long and keep my position... . I could have teleworked for two years. But I wasn't comfortable not getting information directly. We're in the middle of a recession. Even for a man with a wife and kids, it's hard to keep a job. I could lose my job anytime. 


\section{The Nature of the Job}

Work at MNF was characterized by intensity and constant change. The necessity for some employees to report to superiors offshore and to be on international conference calls made it a demanding environment. Depending on one's particular job and configuration within the company, there was a large range in the frequency and duration of overtime that was considered normal. Many women worked overtime until 8 or $9 \mathrm{pm}$ or even midnight until they went on maternity leave, in order to show their dedication and get the extra work finished before they went on leave. Some also took less childcare leave than they were entitled to, in order to get back to their positions as they feared they could not leave the post vacant without losing it. After they returned to work, many women noted how difficult it was to leave early in order to pick up the baby on time from daycare, and they noted frustration at not being able to work on interesting projects with the same intensity as they had before the baby was born. Some solved this by hiring a sitter to pick up the child and wait at home until they arrived; ${ }^{46}$ still others relied on their parents.

Others solved the dilemma of long hours by seeking or accepting job postings that did not require much overtime or by making use of the new "reduced hours for regular workers" policy. This meant, though, that the job was usually much less stimulating, a kind of side-line "mommy track" until they could resume the more intense pace. Some women who were in this sort of position ended up quitting out of sheer frustration, and sought jobs with more flexibility yet more challenging, at other foreign-capital firms.

\section{Overtime and Contingent Workers}

One of the most severe problems facing workers at MNF was long hours of overtime. Although women returning from pregnancy leave or CCL often made use of the firm's policy of reduced working hours for regular employees, they found it very difficult to go home early when their team mates were still at their desks. This occurred at all levels. Women at the managerial level were keenly aware of this problem, as they felt responsible for managing the teamwork. When I asked one employee, if she thought she would have another child, she remarked first that she is getting too old (37), but second, she does not have the confidence to "do all that enryo at work again." ${ }^{7}$ Her boss said it was no problem to put up with her leaving work early every day, since it was just a matter of one or two more years, but, she noted, what that really means is that he is not expecting her to get pregnant again. Another manager with a baby in a public daycare center ultimately quit her job because of the pressure her boss put on her to stay at work late; she had to leave by $6 \mathrm{pm} .^{48}$

Taking reduced hours seemed to work best for those employees who had tasks for which they alone were responsible. In an interview with a top personnel manager in 2002 , I was told that simply returning home at 5:00 pm would make many women the happiest. This manager also noted the unfair disparity between irregular and regular staff, where the former sometimes do overtime, but the latter go home early if they have young children. The differences between conditions for contingent workers and regular workers in the United States in terms of "family friendly" benefits have been studied by Cynthia Deitch and Matt Huffman. They found that although contingent employees with part-time hours are often given more consideration for their families in scheduling, 
Balancing Work and Life: Whose Work? Whose Life? Whose Balance?

part-time work is not ultimately very "family-friendly," as it does not provide the generous family benefits afforded by regular status. ${ }^{49}$ In Japan, the share of women in forms of irregular employment is high. ${ }^{50}$ The fact that FCL and CCL do not apply to these workers leads one to wonder whose balance "family-friendly" policies are aimed at keeping.

\section{Illnesses}

Daycare centers call a mother at work to take the child home if there is even a slight fever, and they also refuse to administer medication. Several informants wished there were daycare for mildly ill children. Children's illnesses were often taken care of by asking relatives to babysit. If there were no other options, the mother would take time off, or hire a professional babysitter, at a cost of over $\$ 200$ per day, or (rarely) ask her spouse or neighbor to help out.

\section{The School-aged Child}

In Japan, schools expect mothers to be home. PTA meetings are usually held during the day, and some mothers ask their mothers or mothers-in-law to attend in their place. If the grandparents do not live with or near the family, children are often sent to after-school care in the school district through the third grade of elementary school. Many of my informants worried about what to do with the children until they (mothers) arrived home in the evening. Sometimes they solved the problem by signing up the child to attend a $j u k u$, a kind of cram school,51 but not all children enjoy this. After-school care for the upper elementary grades is a big worry for dual-income families. It has been raised as a national issue.

Anxieties during the school years focus on the children's emotional, social, and academic development. One informant remarked that the biggest challenge facing her in terms of her working life was that of finding time for family relationships:

I guess... I mean, family relationships, time, me and my husband, we don't have that much, we don't see each other very much ... You know, time with the children. I don't see them in the morning [because she leaves early for work]. I pick them up at $6 \mathrm{pm}$ and all of us had a full day and we're all tired and cranky.

One can see from her account that the stress from lack of balance is not only something parents experience, but is shared by the children as well.

\section{"Balancing": An Impossible Act?}

"Careers" themselves as they are currently defined in Japan, appear to be antithetical to the notion of "balance." In Japan, without grandparents able and willing to assume a large share of the childcare, it is extremely difficult for a dual-earner couple to manage two careers and raise children. While current government initiatives to increase the spaces and hours for babies in daycare centers and to encourage men to spend more time on childrearing may help. However, the root of the problem lies in the high commitment in terms of hours required in the career job. Initiatives toward telecommuting may lighten the burden for some and make "balance" more possible; reduced 
hours seem to be a temporary solution but not long-term.

If overtime could be cut across the board for all workers, the goal of reconciling life with work might be more attainable. Even at MNF, which received a "Family-friendly Award" from the Ministry of Health, Labour and Welfare, many workers felt pinched. From the interviews I have conducted at MNF, it is obvious that at present, women are doing most of the "balancing," and "balance" is precarious as one must respond to an array of changes in both work and home environments. Their husbands, most of whom work for Japanese firms, have little flexibility in their own positions. Fellow staff members of employees taking flexible work arrangements rush to maintain the balance at the office, too, as it is not a practice to hire temporary staff to replace people on leave. Balance, then, is elusive for all concerned.

One must keep in mind that MNF is a large, multinational firm with specific business incentives to retain female career employees. What, then, of Japanese firms? Recall the FFC report cited earlier in this paper. It noted that firms would need more than the incentive of social obligation - that is, the fulfillment of being a good corporate citizen - to embrace "family-friendly" policies. In the current recessionary economy, one doubts if much incentive exists. Indeed, Karen Shire found that some Japanese customer-service firms, even when presented with evidence of inefficiencies spawned by gender-biased work arrangements, opted not to change them. ${ }^{52}$ The mindset that female employees are peripheral and expendable, as in the Japanese corporation that refused to go in with MNF to build a daycare center because it did not want to encourage women to stay on, certainly is an obstacle to the advance of policies to reconcile work and life. On the other hand, there may be certain parts of the private sector where mindsets are changing and incentives do exist. Research on Japanese firms will undoubtedly reveal the complexities of this issue.

The comment of the government official to the effect that many smaller firms see "family-friendly" policies as a luxury comes to mind. One hopes that Japan does not end up with a two-tiered system similar to the one Cynthia Deitch and Mark Huffman have found developing in the United States, with mostly large corporations responding to employees' needs for work/family programs, and women in high-paying or upper-level managerial jobs having more access to such benefits than women in lower paying, mundane jobs. ${ }^{53}$ It is possible that in the manufacturing sector, many jobs will be out-sourced to single, young, female workers abroad whose temporary contracts will certainly not be subject to "family-friendly" standards. One wonders to what extent male and female employees, in an increasingly globalized world, will feel free to utilize "family-friendly" policies.

\section{Footnotes:}

1 The symposium for which I originally wrote this essay was entitled "Challenges for. Japan." One of the biggest challenges is the shape of the population pyramid. In the papers of the 2001 seminar, the topic of the aging society was taken up by Saito Yayoi, who identified the challenge as being how care will be provided and financed in the future for the rapidly aging population. As the author noted, the aging of society is a challenge faced by all Organization for Economic Development (OECD) countries. Japan, a relative late-comer to the problem, but a rapid learner, is in the throes of working out this challenge.

2 "Rapidly aging population to drain workers' wallets," Nikkei Weekly (2 February 2002), p. 4. In this paper we define a "low birthrate society" as one wherein the total fertility rate has dropped beneath the 
replacement level of 2.1 births per woman.

${ }^{3}$ Arlene Appelbaum, Thomas Bailey, Peter Berg, and Arne Kalleberg, Shared Work Valued Care: New Norms for Organizing Market Work and Unpaid Care Work, (Washington, D. C.: Economic Policy Institute, 2002), p. vii.

${ }^{4}$ Working Party on Social Policy, "Family-Friendly Policies: The Reconciliation of Work and Family Life," (Paris: OECD Directorate for Education, Employment, Labour and Social Affairs, Working Paper for $19^{\text {th }}$ Meeting held at the Chateau de la Muette, Paris, 16-17 October 2000).

${ }^{5}$ Nancy Folbre, Who Pays for the Kids ?: Gender and the Structures of Constraint (Routledge: New York, 1994), p. 102.

${ }^{6}$ Mari Osawa, "Twelve Million Full-Time Housewives: The Gender Consequences of Japan's Postwar Social Contract," in Olivier Zunz, Leonard Schoppa, and Nobuhiro Hiwatari, eds., Social Contracts Under Stress: The Middle Classes of America, Europe, and Japan at the Turn of the Century (New York: Russell Sage Foundation, 2002), pp. 255-280.

${ }^{7}$ Eileen Drew, "Re-conceptualizing Families," in Eileen Drew, Ruth Emerek, and Evelyn Mahon, eds., Women, Work and the Family in Europe (New. York: Routledge,1998), pp. 11-26. See also Lillian Rubin, "Getting Younger While Getting Older: Family-Building at Midlife," in Rosanna Hertz and Nancy L. Marshall, eds., Working Families: The Transformation of the American Home (Berkeley: University of California Press, 2001), pp. 58-71.

${ }^{8}$ Drew, "Changing Family Forms and the Allocation of Caring," pp. 27-35, in above, Drew, Emerek, and Mahon, p. 27.

9 Appelbaum, Bailey, Berg, and Kalleberg, Shared Work Valued Care, p. vii.

10 Drew, "Changing Family Forms and the Allocation of Caring" in Drew, Emerek, and Mahon.

11 "Introduction," p. 1-7, by Drew, Emerek, and Mahon, in Drew, Emerek, and Mahon, eds., Women, Work and the Family in Europe, p. 7.

12 Arlie Hochschild, The Second Shift (New York: Avon Books, 1989); See also Scott Coltrane and Michele Adams, "Men's Family Work: Child-Centered Fathering and the Sharing of Domestic Labor," in Hertz and Marshall, eds., Working Families, pp. 72-99.

13 Those born in the year of the horse, in the Chinese astrological calendar, are thought to be strong-willed. As people did not consider this personality trait desirable in a girl, some people avoided giving birth in the Year of the Horse.

${ }^{14}$ Glenda Roberts, "Pinning Hopes on Angels: Reflections from an Aging Japan's Urban Landscape," in Roger Goodman, ed., Family and Social Policy in Japan (Cambridge: Cambridge University Press, 2002), pp. $54-91$.

${ }^{15}$ For an in-depth, inside view of the policy making process for the gender policy-making environment in the past decade, see Mari Osawa, "Government Approaches to Gender Equality in the mid-1990s," Social Science Japan Journal, vol.3, no. 1 (April 2000), pp. 3-19; For more on the Angel Plans see Roberts "Pinning Hopes on Angels," esp. pp. 57-75, 84-86.

${ }^{16}$ Osawa, "Government Approaches to Gender Equality in the Mid-1990s," pp. 3-19.

17 Roberts, "Pinning Hopes on Angels," pp. 54-91.

18 Rodosho Joseikyoku [Ministry of Labour, Women's Bureau], eds., 'Fuamirii Furendorii' Kigyo o Mezashite: 'Fuamirii Furendorii' Kigyo Kenkyokai Hokokusho [Aiming for 'Family Friendly' Firms: A Report from the Study Group on 'Family Friendly' Firms] (Tokyo: Okurasho Insatsukyoku, 2000).

${ }^{19}$ Ibid., p. 4.

20 Sato Hiroki, "Nihon ni okeru 'Fuamirii Furendorii' Seisaku no Genjo to Kadai," ["Current Situation of 'Family Friendly' Policies in Japan"] in Kikan Kakei Keizai Kenkyo [Seasonal Journal of Household Economics] (Spring 2001), pp. 11-17.

${ }^{21}$ Rodosho Joseikyoku (Ministry of Labour, Women's Bureau), eds., 'Fuamrii Furendorii' Kigyo o Mezashite [Aiming for 'Family Friendly' Firms], p. 6.

22 "Paid parental leave pushed for U.S. Workers," International Herald Tribune, (12 March 2002), p. 9.

${ }^{23}$ Rodosho Joseikyoku [Ministry of Labour, Women's Bureau], eds., 'Fuamirii Furendorii' Kigyo o Mezashite [Aiming for 'Family Friendly' Firms], p. 27.

${ }^{24}$ Ibid.

${ }^{25}$ Sato, "Nihon ni okeru 'Fuamirii Furendorii' Seisaku no Genjo to Kadai" ["Current Situation of 'Family 
Friendly' Policies in Japan"], pp. 11-17.

${ }^{26}$ In 1996, firms of 1-4 employees comprised 61.8 percent, and those of under 30 employees comprised 33.0 percent of all firms. 51.8 percent of workers are employed in these small firms. An additional 4.2 percent of firms had between 30-99 employees, and 0.8 of firms had 100-299 employees. Firms of 300 employees or more made up only 0.2 percent of the total, employing 13.2 percent of all workers. See The Japan Institute of Labour, Japanese Working Life Profile 2000-Labour Statistics (Tokyo: Japan Institute of Labour, 2000), p. 30.

27 Marcie Pitt-Catsouphes and Leon Litchfield, "How are Small Businesses Responding to Work and Family Issues ?" in Hertz and Marshall, eds., Working Families, pp. 131-151.

28 The Childcare Leave Law (CCL) was effected in 1992 and Family Care Leave Law (FCL) followed in 1999. CCL allows a one-year childcare leave after childbirth for mother or father or shared; 40 percent of salary is paid by social insurance. FCL allows three-months leave to care for family members in need of care; See Rodosho Joseikyoku [Ministry of Labour, Women's Bureau], 'Fuamirii Furendorii' Kigyo o Mezashite [Aiming for 'Family Friendly' Firms].

29 Ibid., p. 13.

${ }^{30}$ Poto is the Japanese word from the English, "part-timer." It refers to employees of irregular status. The majority of poto work fewer hours than regular employees, but about one-fifth of them work the same hours as regulars for much less in pay and benefits, and no security.

31 There are several points of revision, as follows. Note that only the first section of \#3 and \#5 are mandatory; otherwise, companies are only obliged to "make efforts" or "try" (doryoku gimu):

1. Corporations are obliged to try to provide days for employees who need to take off work for children's illnesses.

2. If an employee has children under primary school age, that employee is limited to working up to 24 hours of overtime per month. The employee may not exceed 150 hours of overtime per year (This was previously unregulated).

3. Short-hours work schedules have been expanded to cover people with children up to age three. From age three to the beginning of primary school, there is no regulation, but companies are expected to make efforts. (The previous regulation was only to age one, with companies expected to make efforts thereafter until the child reached school age).

4. Corporations should give consideration to workers, vis a vis transfers (not previously stated in the law).

5. Corporations are forbidden to demote employees, lower their wages or give them other undesirable (furieki) treatment (formerly, only dismissal was forbidden).

See Asahi Shimbun, "Kodomo no Byoki de Dodo to Yasumeru? Kangokyoka Seido Sutoto Gemba wa" ["Can You Go Right Ahead and Take Time Off for Your Children's Illnesses? Down in the Trenches with the Family Care Leave System"] (19 April 2002), p. 23.

32 See Alice Cook and Hiroko Hayashi, Working Women in Japan: Discrimination, Resistance, and Reform (Ithaca, N.Y.: Cornell University Press, 1980).

33 For further discussion of this topic, see Roberts, "Pinning Hopes on Angels," pp. 54-91.

${ }^{34}$ Kokumin Seikatsu Hakusho Heisei 13 Nendo [People's Lifestyle White Paper for 2001] (Tokyo: Naikakufu [Cabinet Office], 2001), p. 13.

35 Ibid., p. 15

36 Statistics were compiled from data of the Naikakufu, Kokumin Seikatsu Senkodo Chosa [Survey on People's Lifestyle Preferences] (Tokyo: Naikakufu [Cabinet Office], 2001).

1. Graph reflects the proportion of responses to the question, "Can you have an abundant and satisfying life without marrying?"

2. "Yes" answers are a combination of those who responded, "Yes, I think so," and, "I pretty much think so." "No" answers are a combination of those who responded, "No, I don't think so," and, "I don't really think so." Reponses of "I can't say either way" and blank responses were not included.

3. 2,527 people responded to the survey.

37 Ibid., pp. 7-8.

38 "Rapidly Aging Population to Drain Workers' Wallets," Nikkei Weekly, 2 February 2002, p. 4.

39 Statistical information is based on data taken from the "Statistical Abstract of the United States," (US 
Department of Commerce, 2000) and the "Basic Survey of Employment Structure," (Ministry of General Affairs, 1997). In the U.S. data, "employment rate" is labor force participation rate. "ages 6-14" = ages 613; "ages 15-17"=ages $14-17$.

40 For further treatment on the debates over "fatherhood," see Roberts, "Pinning Hopes on Angels," esp. pp. 76-84.

41 See Margaret Lock, "Centering the Household: The Remaking of Female Maturity in Japan," in Anne Imamura, ed., Re-imaging Japanese Women (Berkeley: University of California Press, 1996), pp. 73-103; Mari Osawa, "Bye-bye Corporate Warriors: The Formation of a Corporate Centered Society and GenderBiased Social Policies," in University of Tokyo Institute of Social Science Occasional Papers in Labor Problems and Social Policy, no. 18, (March, 1994), and Glenda Roberts, Staying on the Line: Blue-Collar Women in Contemporary Japan (Honolulu: University of Hawaii Press, 1994).

${ }^{42}$ Osawa Mari, Kigyo Chushin Shakai o Koete: Gendai Nihon o "Jenda" de Yomu [Overcoming the CorporateCentered Society: Reading Contemporary Japan through Gender] (Tokyo: Jiji Tsushin, 1993).

43 Takie Lebra, Japanese Women: Constraint and Fulfilment (Honolulu: University of Hawaii Press, 1984); Sumiko Iwao, The Japanese Woman: Traditional Image and Changing Reality (New York: Free Press, 1993); Robin LeBlanc, Bicycle Citizens: The Political World of the Japanese Housewife (Berkeley: University of California Press, 1999).

44 This policy allowed workers to reduce their hours to 60 percent for a legitimate reason (such as study or family care) without entailing a loss of benefits. It could be utilized for up to one year, upon which the case would be reviewed. It was offered on a case-by-case basis. It was above and beyond the legal stipulation for a "family-friendly" policy.

45 The U.S. government did pass the Family Medical Leave Act (FMLA) in 1993, in recognition of the difficulties workers have in dealing with life-course related events. See Blau, 1996, "Comment," on Aileen Leibowitz, "Childcare: Private Cost or Public Responsibility ?" in Victor Fuchs, ed., Individual and Social Responsibility: Childcare, Education, Medical Care, and Long-term Care in America (Chicago: University of Chicago Press, 1996). Also, Christopher J. Ruhm and Jacqueline L.Teague, "Parental Leave Policies in Europe and North America," in Francine Blau and Ronald Ehrenberg, eds., Gender and Family Issues in the Workplace (New York: Russell Sage Foundation, 1997), pp. 133-156. The FMLA allows up to three months' unpaid leave for family care, but it does not apply to workers in companies with fewer than fifty employees. Aside from using vacation time or sick leave, many employees use the FMLA for maternity leave, as there is no federally mandated leave for maternity in the United States. As it is unpaid, limited to three months, and not applicable to workers in smaller firms, one can see that the FMLA offers workers significantly less flexibility than does Japan's CCL.

${ }^{46}$ Most women used daycare centers near their homes so as to avoid commuting with babies. A commute of over an hour each way was usual.

47 The word "enryo" literally means to hesitate or refrain from doing something. What she means by "doing enryo" is to be very careful always to apologize in advance and prepare fully if she has to leave early or be absent (which would most certainly happen if she takes maternity leave, childcare leave, or reduced hours after returning to work), to cause as little inconvenience as possible, and to make sure she demonstrates to her co-workers and boss how sorry she is for causing them inconvenience.

48 The reader might wonder why this employee did not hire a domestic worker to cover her overtime. Most of the women I interviewed do not employ domestic help. Part of the reason is cost and availability, due to a shortage of Japanese women willing to be domestic help, which makes such help expensive, combined with restrictive immigration laws. There is also some reluctance to allow strangers into the home to perform care work.

${ }^{49}$ Cynthia Deitch and Matt Huffman, "Family-Responsive Benefits and the Two-Tiered Labor Market," in Hertz and Marshall, Working Families, pp. 102-130.

50 Mari Osawa, "People in Irregular Modes of Employment: Are They Really Not Subject to Discrimination ?," Social Science Japan Journal, vol. 4, no. 2 (October 2001), pp. 183-199.

51 Juku are private schools children attend for supplementary academic lessons, for preparation to take rigorous entrance exams, or for enrichment, such as music, art, calligraphy, or abacus.

${ }^{52}$ Karen Shire, "Gendered Organization and Workplace Culture in Japanese Customer Services," Social Science Japan Journal, Vol. 3, No. 1 (April 2000), pp. 37-58. 


\section{Glenda S. Roberts}

${ }^{53}$ Deitch and Huffman, "Family-Responsive Benefits," pp. 102-130. 